\title{
Radial nerve palsy in the newborn
}

\author{
Claire T. Lundy MB MSc
}

See related research article by Alsubhi and colleagues on page 1367 and at www.cmaj.ca/lookup/doi/10.1503/cmaj.110272.

Competing interests: None declared.

This article was solicited and has not been peer reviewed.

\section{Correspondence to:} Dr. Claire Lundy, claire.lundy1@belfasttrust .hscni.net

CMAJ 2011. DOI:10.1503 /cmaj.110972
I solated radial nerve palsy in the newborn is uncommon. However, pediatricians and primary care physicians need to be aware that it has a good prognosis, particularly if the history and clinical examination suggest a palsy related to intrauterine pressure.

In this issue of CMAJ, Alsubhi and colleagues ${ }^{1}$ describe the largest case series of infants with isolated radial nerve palsy in the medical literature to date. Previous commentaries and case reports have described clinical findings that are consistently associated with transient radial nerve palsy. ${ }^{2-4}$ Morgan described a bruised appearance in the upper limb associated with wrist drop in the infant after prolonged labour. ${ }^{4}$ Subsequent reports emphasized the link between radial nerve palsy, long labour and areas of subcutaneous fat necrosis indicative of possible intrauterine pressure. Some of these reports clearly describe the presenting position of the newborn: arms flexed and hands tucked under the axillae, which could expose the relatively superficial part of the radial nerve to intrauterine pressure. Figure 1 shows the anatomy of the radial nerve in the adult arm, and an accompanying description can be found in Box 1.2-5

With their retrospective study involving 25 infants with isolated radial nerve palsy, Alsubhi and colleagues help to place these previous reports of the condition in context for family physicians and pediatricians. Recovery occurred over a period ranging from one week to six months. Most infants recovered (72\%) within two months, and all infants recovered fully.

This study has limitations. Alsubhi and colleagues stress that they relied on referrals to their brachial plexus injury clinic and recognize that there may have been underreporting, particularly of milder cases. Because nerve con-

\section{- KeY POINTS}

- Isolated radial nerve palsy in the newborn is uncommon.

- Full recovery should occur within six months if the condition is due to superficial pressure applied in utero.

- Other causes of weakness in the upper limbs of the newborn should be carefully considered.

duction studies might cause distress to an infant, they were not routinely performed by the authors when the clinical presentation was consistent with isolated radial nerve palsy. In addition, a number of infants improved without any intervention such as splinting or physiotherapy and appeared to have normal function when examined in the clinic. For these patients, the authors depended on the clinical description provided by the referring physician and family.

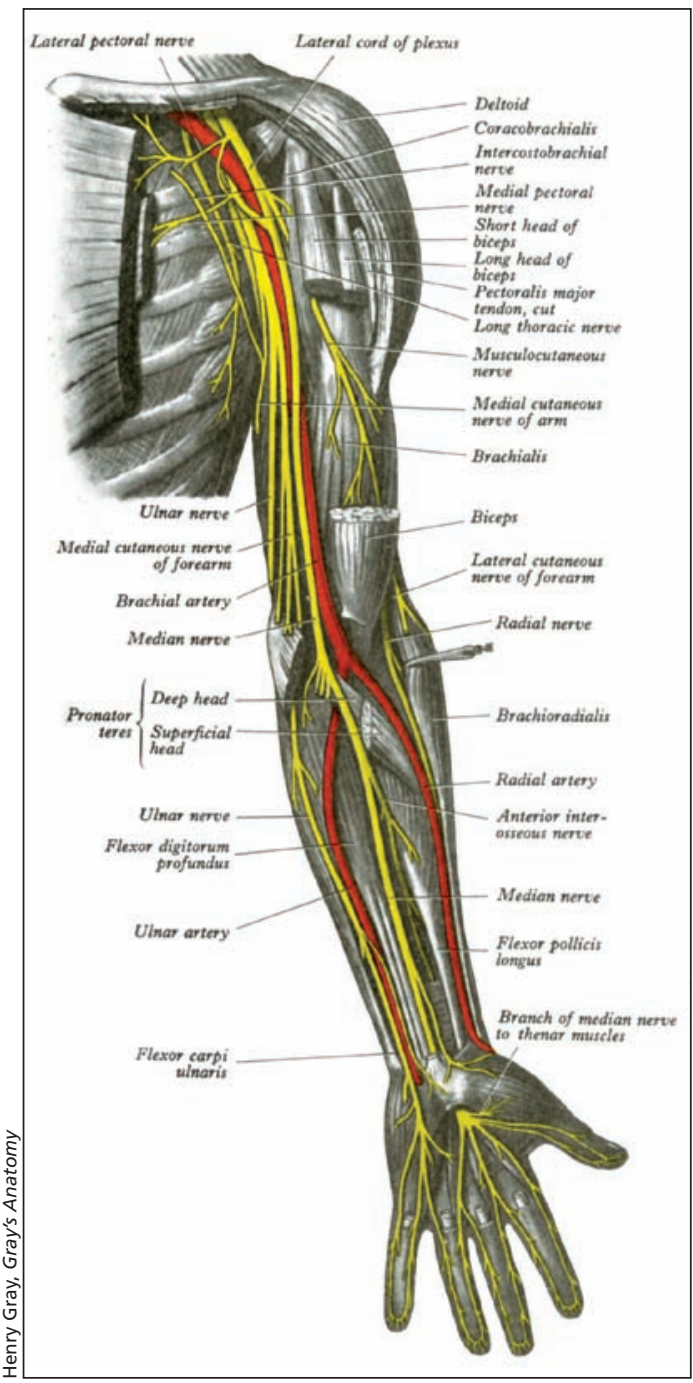

Figure 1: Innervation of the adult left upper limb (see also Box 1). 


\section{Box 1: The radial nerve}

The radial nerve originates from the posterior cord of the brachial plexus (nerves C5 through T1). From there, it traverses the triangular space of the axilla and supplies the medial and lateral heads of triceps brachii. The nerve then runs relatively superficially in the radial groove of the humerus before running alongside the brachial artery toward the forearm, anterior to the lateral epicondyle. It is therefore an important motor nerve supplying muscles including the triceps, brachioradialis, extensor carpi radialis, supinator, extensor carpi ulnaris and extensor digitorum. The radial nerve also has a superficial sensory branch. Lesions of the radial nerve can result in the characteristic appearance of wrist drop.

Isolated radial nerve palsy is characterized by normal movements of the shoulder and flexion of the elbow. The radial nerve is felt to be vulnerable to pressure-related damage owing to its superficial course. This has been described with certain techniques for monitoring blood pressure in newborns. ${ }^{5}$

It is therefore difficult to ascertain the impact that passive movement of the wrist and arm through the full range of motion or splinting might have had on these patients. In most of the previously reported cases, the practice of splinting and passive movement of the wrist and arm was started as soon as the condition was diagnosed. Within a relatively short time there was some appearance of recovery, and most children recovered full function, some by three months of age.

Radial nerve palsy needs to be differentiated from serious avulsion injuries of the brachial plexus. Brachial plexus palsy has a less favourable prognosis, and surgical intervention in the form of grafting and nerve transfer may be required. ${ }^{6}$ The reported incidence of these types of injury varies from $0.1 \%-4.0 \%$ of live births. ${ }^{7}$ Some authors advocate early surgical intervention when there is an avulsion to ensure the child has the best chance of improving motor function. Recovery after surgery may take four years or longer owing to the time needed for axonal growth to occur, and sensory deficits can persist.

Pediatricians may see isolated radial nerve palsy in the newborn only once or twice during their careers. When faced with the possibility of this diagnosis, a careful neurologic assessment of the infant can help the clinician to exclude other causes of weakness in the upper limb, particularly if the weakness is bilateral. Consultation with specialists in neurology or orthopedics may be necessary for a formal diagnosis. Clinicians assessing these infants should recognize the clinical signs of radial nerve palsy and initiate supportive therapy where necessary while reassuring the family.

\section{References}

1. Alsubhi FS, Althunyan AM, Curtis CG, et al. Radial nerve palsy in the newborn: a case series CMAJ 2011;183:1367-70.

2. Feldman GV. Radial nerve palsies in the newborn. Arch Dis Child 1957;32:469-71.

3. Lightwood R. Radial nerve palsy associated with localized subcutaneous fat necrosis in the newborn. Arch Dis Child 1951;26:436-7.

4. Morgan L. Radial nerve paralysis in the newborn. Arch Dis Child 1948;23:137-9.

5. Weindling AM. Blood pressure monitoring in the newborn. Arch Dis Child 1989;64:444-7.

6. Strömbeck C, Krumlinde-Sundholm L, Forssberg H. Functional outcome at 5 years in children with obstetrical brachial plexus palsy with and without microsurgical reconstruction. Dev Med Child Neurol 2000;42: 148-57.

7. Anand P, Birch R. Restoration of sensory function and lack of long-term chronic pain syndromes after brachial plexus injury in human neonates. Brain 2002;125:113-22.

Affiliation: Dr. Claire T. Lundy is with the Royal Belfast Hospital for Sick Children, Belfast, Northern Ireland. 